\title{
TINGGI BADAN IBU SEBAGAI FAKTOR RISIKO STUNTING PADA ANAK USIA 24-59 BULAN DI KECAMATAN PLERET DAN KECAMATAN PAJANGAN, KABUPATEN BANTUL, YOGYAKARTA
}

\author{
Wiwid Andari ${ }^{1}$, Tri Siswati ${ }^{2}$, Bunga Astria Paramashanti ${ }^{*}$ \\ ${ }^{1}$ Program Studi Gizi, Fakultas Ilmu-ilmu Kesehatan, Universitas Alma Ata. Jalan Brawijaya No. 99 Kasihan, Bantul, Daerah Istimewa Yogyakarta \\ 55183, Indonesia \\ ${ }^{2}$ Poltekkes Kemenkes Yogyakarta. Jalan Tata Bumi No. 3, Gamping, Sleman, Daerah Istimewa Yogyakarta 55293, Indonesia \\ ${ }^{*}$ Penulis Penanggungjawab: E-mail: bunga@almaata.ac.id
}

\begin{abstract}
Background: The prevalence of stunting among children under the age of five years old in Indonesia remained high (30.8\%). One of the risk factors of stunting is chronic intergenerational malnutrition cycle between mothers and children. Objectives: To analyze whether maternal height was a risk factor of stunting among children aged 24-59 months in Pleret and Pajangan Subdistricts, Bantul District.

Methods: This study used case-control design with a total of 43 cases and 43 controls. All subjects were selected using multistage cluster sampling. Independent variable was stunting whereas dependent variable was maternal height. Data were analyzed using descriptive statistics, chi-square test, and multiple logistic regression.

Results: Maternal height was a predictor of childhood stunting (adjusted OR= 2,720; 95\%CI: 1,050-7,049). Other variables such as paternal height, parental educational attainment, parental type of occupation, and child's sex were not risk factors of stunting.

Conclusion: Maternal height is a risk factor of stunting among children aged 24-59 months. Interventions focused on the first 1000 days of life are needed to prevent childhood stunting caused by the intergenerational cycle of malnutrition.
\end{abstract}

Keywords: stunting; maternal height; malnutrition cycle; children

\begin{abstract}
ABSTRAK
Latar belakang:Prevalensi stunting pada balita di Indonesia masih tinggi (30,8\%). Salah satu faktor risiko stunting yaitu siklus malnutrisi kronis antar generasi yang terjadi antara ibu dan anak.

Tujuan: Untuk menganalisis apakah tinggi badan ibu merupakan factor risiko stunting pada anak usia 24-59 bulan di Kecamatan Pleret dan Kecamatan Pajangan, Kabupaten Bantul, Daerah Istimewa Yogyakarta.

Metode: Penelitian ini menggunakan rancangan kasus kontrol dengan total kasus sejumlah 43 anak dan total kontrol sebanyak 43 anak. Seluruh sampel diambil dengan menggunakan teknik pengambilan sampel multistage cluster sampling. Variabel dependen yang diteliti adalah stunting, sedangkan variabel independent adalah tinggi badan ibu. Data dianalisis dengan menggunakan deskriptif statistik, uji chi-square dan regresi logistik ganda.

Hasil: Tinggi badan ibu secara signifikan merupakan prediktor stunting (adjusted OR= 2,720; 95\% CI: 1,050-7,049). Faktor lain seperti tinggi badan ayah, tingkat pendidikan ayah dan ibu, jenis pekerjaan ayah dan ibu, serta jenis kelamin anak bukan merupakan faktor risiko stunting.

Simpulan: Tinggi badan ibu merupakan faktor risiko stunting pada anak usia 24-59 bulan. Intervensi yang difokuskan pada periode 1000 hari pertama kehidupan dibutuhkan untuk mencegah terjadinya stunting akibat dari siklus malnutrisi antar generasi.
\end{abstract}

Kata Kunci: stunting; tinggi badan ibu; siklus malnutrisi, anak

\section{PENDAHULUAN}

Stunting merupakan indikator dari masalah kesehatan masyarakat pada balita yang terjadi baik di negara berkembang, termasuk di Indonesia. Secara global, sebanyak 149 juta anak atau $21,9 \%$ anak di bawah usia lima tahun mengalami stunting pada tahun 2018 dimana setengah dari jumlah tersebut berada di Asia. ${ }^{1}$ Di Indonesia, prevalensi stunting mencapai 30,8\% pada tahun 2018. ${ }^{2}$ Bahkan seperempat dari anak-anak tersebut sudah mengalami stunting sejak masa prenatal. ${ }^{3}$ Prevalensi stunting di Daerah Istimewa Yogyakarta sebesar 21,4\%. ${ }^{2}$ Prevalensi ini tidak jauh berbeda dengan hasil penelitian di Kecamatan Sedayu, Kabupaten Bantul, yaitu 21,3\%. ${ }^{4}$ Meskipun prevalensi stunting di Kabupaten Bantul di bawah prevalensi nasional, namun prevalensi ini masih tergolong tinggi (20$30 \%){ }^{5}$

Di Indonesia, sejumlah upaya dilakukan untuk menurunkan angka stunting. Pemerintah Indonesia memproyeksikan target penurunan angka stunting menjadi $22 \%$ pada tahun $2022 .{ }^{6}$ Di bawah koordinasi Kementrian Koordinator Bidang Pembangunan Manusia dan Kebudayaan, pemerintah menetapkan 100 kabupaten/kota sebagai prioritas penanganan stunting pada tahap pertama di tahun 2018. Prioritas 
ini dibuat berdasarkan tingginya proporsi stunting dan tingkat kemiskinan penduduk di kota/kabupaten tersebut. ${ }^{7}$ Pada tahun 2019, wilayah sasarannya diperluas menjadi 160 kabupaten/kota. Di tahap ke-2 ini, Kabupaten Bantul termasuk di dalam salah satu kabupaten/kota yang diprioritaskan. ${ }^{8}$

Faktor-faktor ibu memainkan peran penting dalam siklus stunting antar generasi dari ibu ke anak. Pada tahap prakonsepsi, ibu yang pendek berisiko memiliki anak yang stunting. ${ }^{9}{ }^{9} 10$ Apabila pada masa kehamilan, ibu memiliki asupan yang tidak adekuat ${ }^{11}$, ${ }^{12}$, menderita penyakit infeksi ${ }^{9}$, dan terpapar polusi dari lingkungan ${ }^{9}$, maka risiko stunting pada anak akan meningkat. Selain itu, kehamilan remaja, jarak kelahiran yang pendek, hipertensi, dan kondisi kesehatan mental ibu juga berpengaruh terhadap risiko stunting pada anak. ${ }^{13}$

Sejumlah penelitian dilakukan untuk mengetahui hubungan antara faktor-faktor ibu dengan stunting. Namun, penelitian-penelitian yang dilakukan di beberapa wilayah Indonesia sebagian besar menggunakan rancangan potong lintang ${ }^{14-17}$ dan menunjukkan hasil yang tidak bermakna atau tidak konsistensi ${ }^{16-18}$. Hasil yang bervariasi ini kemungkinan disebabkan oleh sifat alamiah stunting yang kontekstual menyesuaikan dengan faktor komunitas dan sosial di populasi. ${ }^{13,19}$

Kegagalan tumbuh pada anak terjadi dengan cepat pada usia dua tahun pertama kehidupan. Setelah usia 24 bulan, rerata skor Z tinggi badan menurut usia anak cenderung stagnan, tanpa penurunan ataupun peningkatan. ${ }^{20}$ Oleh karena itu, untuk menangkap faktor-faktor risiko stunting pada dua tahun pertama kehidupan anak secara utuh, maka penelitian ini bertujuan untuk menganalisis hubungan antara tinggi badan ibu dan stunting pada anak usia 24-59 bulan di Kecamatan Pleret dan Kecamatan Pajangan, Kabupaten Bantul. Rancangan kasus kontrol digunakan untuk mengidentifikasi prediktor dari stunting.

\section{METODE}

Penelitian yang menggunakan rancangan kasus kontrol ini dilaksanakan di Kecamatan Pleret dan Kecamatan Panjangan, Kabupaten Bantul, Daerah Istimewa Yogyakarta pada bulan September 2018 hingga Januari 2019. Populasi adalah seluruh anak usia 24 - 59 bulan di Kecamatan Pleret dan Kecamatan Pajangan, Kabupaten Bantul. Sampel adalah anak usia 24 - 59 bulan yang tinggal menetap di Kecamatan Pleret dan Kecamatan Pajangan, dimana kasus adalah anak usia 24 - 59 bulan yang memiliki skor-Z tinggi badan menurut umur $(\mathrm{TB} / \mathrm{U})<-2 \mathrm{SD}$, sedangkan kontrol adalah anak usia 24 - 59 bulan dengan
TB/U $\geq-2$ SD. Seluruh ibu dari subjek penelitian menyatakan kebersediaannya untuk mengikuti penelitian ini dengan menandatangani formulir informed consent. Penelitian ini telah melalui uji kelayakan etik dari Universitas Alma Ata (KE/AA/II/779/EC/2019).

Besar sampel minimal yang dibutuhkan pada penelitian ini adalah 36 untuk masing-masing kasus dan kontrol atau dengan kata lain 72 secara total berdasarkan rumus Lemeshow. ${ }^{21}$ Pada pelaksanaannya, jumlah sampel ini dilebihkan sebesar $10 \%$ sehingga didapatkan total minimal sampel 80 anak. Teknik pengambilan sampel pada penelitian ini menggunakan multistage cluster sampling dengan total delapan klaster, yaitu lima desa di wilayah kerja Puskesmas Pleret dan tiga desa di wilayah kerja Kecamatan Pajangan. Seluruh anak yang terdaftar di posyandu di delapan desa tersebut dikategorikan menjadi stunting dan tidak stunting untuk membuat sampling frame bagi kasus dan kontrol berdasarkan data Penilaian Status Gizi pada bulan Februari 2018 sebagai data awal untuk pemilihan posyandu. Pada tahap pertama, 29 posyandu dari total 109 posyandu yang berlokasi di desa-desa di kedua kecamatan tersebut dipilih secara acak (lotere). Dua puluh sembilan posyandu dipilih berdasarkan data sekunder ratarata jumlah anak stunting adalah sekitar tiga anak per posyandu. Pada tahap kedua, convenient sampling digunakan dalam memilih kasus dari setiap posyandu terpilih berdasarkan kedatangan anak. Di posyandu terpilih, kami mengukur kembali tinggi badan anak saat ini dan menentukan status stunting pada anak berdasarkan usia anak saat pengambilan data berlangsung. Kontrol dipilih dari posyandu yang sama dengan kasus.

Variabel dependen pada penelitian ini adalah stunting pada anak. Stunting didefinisikan sebagai skor-Z tinggi badan per umur $(\mathrm{TB} / \mathrm{U})<-2 \mathrm{SD}$ berdasarkan referensi pertumbuhan $\mathrm{WHO}^{22}$ Variabel independen adalah tinggi badan ibu. Tinggi badan ibu dibagi menjadi dua kategori, yaitu $<150 \mathrm{~cm}$ dan $\geq 150 \mathrm{~cm} .{ }^{23}$ Variabel lain yang diteliti meliputi tinggi badan ayah, tingkat pendidikan ibu, tingkat pendidikan ayah, jenis pekerjaan ibu, jenis pekerjaan ayah dan jenis kelamin anak.

Jenis kelamin perempuan dijadikan sebagai referensi karena anak laki-laki cenderung lebih berisiko untuk mengalami stunting. Perbedaan biologis akibat defisiensi imun relatif (relative immunodeficiency) meningkatkan risiko morbiditas dan mortalitas yang lebih besar pada anak laki-laki daripada anak perempuan di awal masa kehidupannya. Selain itu, anak laki-laki 
cenderung terpapar pemberian makanan pendamping ASI sebelum usia 6 bulan dan mengalami tumbuh kejar yang lebih lambat daripada anak perempuan. ${ }^{24}$

Tinggi badan ayah digolongkan menjadi $<162 \mathrm{~cm}$ dan $\geq 162 \mathrm{~cm}^{23}$ Tingkat pendidikan ibu dan ayah tergolong rendah jika tamat SMP atau jenjang pendidikan di bawahnya, dan tinggi jika tamat SMA atau di atasnya. Adapun jenis pekerjaan ibu dan ayah termasuk dikategorikan menjadi nonagricultural sector seperti pegawai negeri, pegawai swasta, atau wiraswasta, dan agricultural sector yang meliputi petani, buruh tani, nelayan, peternak dan semacamnya.

Seluruh data pada penelitian ini dianalisis dengan analisis univariat yaitu deskriptif statistik, analisis bivariat dengan uji chi-square dan analisis multivariat dengan regresi logistik ganda. Variabel dengan nilai $p<0,25$ pada uji bivariat dianalisis lebih lanjut pada analisis multivariat. Setelah itu, peneliti memilih model yang paling parsimonious sebagai model akhir hubungan antara tinggi badan ibu dan stunting dengan level signifikansi $p<0,05$. Analisis dilakukan dengan menggunakan SPSS versi 16.0 for windows.

\section{HASIL}

Tabel 1. Distribusi Karakteristik Anak Usia 24-59 Bulan dan Keluarga

\begin{tabular}{lrrrr}
\hline \multicolumn{1}{c}{ Variabel } & \multicolumn{2}{c}{ Kasus } & \multicolumn{2}{c}{ Kontrol } \\
\cline { 2 - 5 } & n & \% & n & \% \\
\hline Jenis kelamin & & & & \\
$\quad$ Laki-laki & 23 & 53,49 & 23 & 53,49 \\
$\quad$ Perempuan & 20 & 46,51 & 20 & 46,51 \\
Pekerjaan ayah & & & & \\
$\quad$ Agricultural & 41 & 95.35 & 41 & 95.35 \\
$\quad$ Non-agricultural & 2 & 4,65 & 2 & 4,65 \\
Pendidikan ayah & & & & \\
$\quad$ Rendah & 18 & 41,86 & 11 & 25,58 \\
$\quad$ Tinggi & 25 & 58,14 & 32 & 74,42 \\
Pendidikan ibu & & & & \\
$\quad$ Rendah & 16 & 37,21 & 13 & 30,23 \\
$\quad$ Tinggi & 27 & 62,79 & 30 & 69,77 \\
Tinggi badan ibu & & & & \\
$\quad<150 \mathrm{~cm}$ & 18 & 41,86 & 9 & 20,93 \\
$\quad \geq 150 \mathrm{~cm}$ & 25 & 58,14 & 34 & 79,07 \\
Tinggi badan ayah & & & & \\
$\quad<162 \mathrm{~cm}$ & 7 & 16,28 & 3 & 6,98 \\
$\quad \geq 162 \mathrm{~cm}$ & 36 & 83,72 & 40 & 93,02 \\
\hline
\end{tabular}

Total subjek pada penelitian ini sebanyak 86 anak usia 24-59 bulan yang terdiri dari 43 kasus dan 43 kontrol. Tabel 1 menunjukkan distribusi karakteristik anak dan orang tua. Pada kelompok kasus sebagian besar ayah dan ibu berpendidikan tinggi atau minimal tamat SMA dengan masing- masing 58,14\% dan 62,79\%. Mayoritas ibu bertinggi badan $\geq 150 \mathrm{~cm}$ baik di kelompok kasus $(58,14 \%)$ maupun kelompok kontrol $(79,07 \%)$. Begitu pula dengan ayah yang sebagian besar bertinggi badan $\geq 162 \mathrm{~cm}$ baik di kelompok kasus $(83,72 \%)$ maupun kelompok kontrol $(93,02 \%)$.

Tabel 2 menyajikan hasil uji chi-square untuk melihat faktor-faktor yang berhubungan dengan stunting pada anak usia 24 hingga 59 bulan. Satusatunya variabel yang signifikan berhubungan dengan stunting, yaitu tinggi badan ibu. Ibu yang bertinggi badan pendek $(<150 \mathrm{~cm})$ cenderung memiliki anak yang berisiko stunting 2,7 kali lebih besar daripada ibu dengan tinggi badan $\geq 150 \mathrm{~cm}$ (95\% CI: 1,05-7,05). Adapun variabel lain seperti jenis kelamin, pekerjaan ayah, pendidikan ayah, dan tinggi badan ayah tidak berhubungan dengan stunting pada anak usia 24-59 bulan. Meskipun begitu, seluruh variabel dengan $p<0,25$ pada uji chi-square dimasukkan ke dalam analisis multivariat. Variabelvariabel tersebut meliputi tinggi badan ibu $(\mathrm{p}=0,035)$ pendidikan ayah $(\mathrm{p}=0,109)$ dan tinggi badan ayah $(\mathrm{p}=0,173)$.

Tabel 2. Hasil Analisis Bivariat Faktor-Faktor Risiko Stunting pada Anak Usia 24-59 Bulan

\begin{tabular}{|c|c|c|}
\hline Variabel & $\begin{array}{c}\text { Crude OR } \\
(95 \% \text { CI })\end{array}$ & $p$ \\
\hline \multicolumn{3}{|l|}{ Jenis kelamin } \\
\hline Perempuan & 1 & \\
\hline Laki-laki & $1,00(0,43-2,33)$ & 1,000 \\
\hline \multicolumn{3}{|l|}{ Pekerjaan ayah } \\
\hline Non-agricultural & 1 & \\
\hline Agricultural & $1,00(0,13-7,44)$ & 1,000 \\
\hline \multicolumn{3}{|l|}{ Pendidikan ayah } \\
\hline Tinggi & 1 & \\
\hline Rendah & $2,10(0,84-5,23)$ & 0,109 \\
\hline \multicolumn{3}{|l|}{ Pendidikan ibu } \\
\hline Tinggi & 1 & \\
\hline Rendah & $1,23(0,51-2,98)$ & 0,651 \\
\hline \multicolumn{3}{|l|}{ Tinggi badan ibu } \\
\hline$\geq 150 \mathrm{~cm}$ & 1 & \\
\hline$<150 \mathrm{~cm}$ & $2,72(1,05-7,05)$ & $0,035 *$ \\
\hline \multicolumn{3}{|l|}{ Tinggi badan ayah } \\
\hline$\geq 162 \mathrm{~cm}$ & 1 & 0,173 \\
\hline$<162 \mathrm{~cm}$ & $2,59(0,62-10,78)$ & 0,173 \\
\hline
\end{tabular}

Setelah memasukkan variabel tinggi badan ibu, pendidikan ayah dan tinggi badan ayah ke dalam analisis multivariat seperti disajikan dalam Tabel 3, peneliti memformulasikan tiga model. Diantara ketiga model tersebut, model ketiga dipilih karena dirasa paling baik menjelaskan model yang parsimonious. Pada model ini, tinggi badan ibu berhubungan signifikan dengan peningkatan risiko stunting pada anak usia 24-59 bulan di Kabupaten Bantul (OR=2,72; 95\%CI: 1,05-7,05). 
Tabel 3. Hasil Analisis Mulivariat Faktor-Faktor Risiko Stunting pada Anak Usia 24-59 Bulan

\begin{tabular}{lccc}
\hline Variabel & Model 1 & Model 2 & Model 3 \\
\cline { 2 - 4 } & AOR & AOR & AOR \\
$(\mathbf{9 5 \%}$ CI $)$ & $\mathbf{( 9 5 \% ) ~ C I ) ~}$ & \\
\hline Pendidikan ayah & 2,08 & 2,08 & $(0,81-5,30)$ \\
$\quad$ Rendah & $(0,81-5,34)$ & 1 & $2,72 *$ \\
Tinggi & 1 & $2,70 *$ & $(1,05-7,05)$ \\
TB Ibu & 2,57 & $(1,03-7,09)$ & 1 \\
$<150 \mathrm{~cm}$ & $(0,97-6,82)$ & 1 & \\
$\geq 150 \mathrm{~cm}$ & 1 & & \\
TB Ayah & 2,23 & & \\
$<162 \mathrm{~cm}$ & $(0,50-9,92)$ & & \\
$\geq 162 \mathrm{~cm}$ & 1 & &
\end{tabular}

\section{PEMBAHASAN}

Penelitian ini menunjukkan bahwa ibu dengan tinggi badan yang pendek $(<150 \mathrm{~cm})$ memiliki risiko untuk memiliki anak stunting sebesar 2,7 kali lebih besar dibandingkan dengan ibu bertinggi badan normal $(\geq 150 \mathrm{~cm})$. Sebuah penelitian analisis lanjut dari Riskesdas 2013 menunjukkan bahwa ibu dengan tinggi badan $<145 \mathrm{~cm}$ dikaitkan dengan risiko stunting pada anak sebesar dua kali lipat lebih tinggi bandingkan dengan ibu yang memiliki tinggi badan $\geq 145 \mathrm{~cm} .{ }^{25}$ Penelitian lain yang dilakukan di Kabupaten Gianyar, Bali, menunjukkan ibu dengan tinggi badan yang pendek $(<150 \mathrm{~cm})$ cenderung memiliki anak yang stunting. ${ }^{14}$ Terlebih lagi, penelitian yang dilakukan di Ghana, Malawi dan Burkina Faso menunjukkan bahwa faktor ibu merupakan variabel yang lebih konsisten dan lebih kuat dihubungkan dengan skor-Z tinggi badan per umur pada anak apabila dibandingkan dengan faktor lingkungan dan pola asuh. Di antara faktor ibu tersebut, tinggi badan ibu merupakan salah satu prediktor yang paling konsisten. ${ }^{26}$

Sebuah penelitian yang dilakukan di 57 negara menunjukkan bahwa tinggi badan ibu dapat mempengaruhi ukuran bayi saat lahir yang kemudian menentukan trayektori pertumbuhan postnatal. ${ }^{27}$ Prendergast et al memaparkan mekanisme yang disebut dengan sindroma stunting melalui jalur antar generasi. Wanita hamil yang pendek berisiko memiliki janin yang terhambat pertumbuhannya, terlebih jika diiringi dengan konsumsi makan yang inadekuat, infeksi, dan terpapar polusi selama kehamilan. Janin dengan rektrisi pertumbuhan akan berpeluang untuk berukuran kecil atau prematur saat dilahirkan. Apabila bayi yang lahir ini kemudian tidak diberikan asupan yang adekuat baik dari ASI maupun MP-ASI, mengalami infeksi berulang, praktik higiene dan sanitasi yang buruk, serta mendapat pola asuh yang buruk, maka akan menjadi bayi atau anak yang kerdil atau stunting. ${ }^{9}$ Sebagaimana penelitian sebelumnya di Kabupaten
Bantul, anak yang terlahir dengan berat badan $<2500$ $\mathrm{g}$ cenderung tumbuh menjadi anak yang stunting. ${ }^{28}$

Tinggi badan ibu dapat mempengaruhi pertumbuhan linear anak selama periode pertumbuhan yang mencakup faktor genetik dan nongenetik. ${ }^{29}$ Pada level individu, tinggi badan ibu dikaitkan dengan potensi genetik anak untuk mencapai tinggi badannya di masa dewasa. Di populasi dimana prevalensi stunting tergolong tinggi, tinggi badan ibu juga merefleksikan riwayat restriksi pertumbuhan yang dialami oleh ibu di awal masa kehidupannya. Kondisi sosio-ekonomi dapat memediasi efek pertumbuhan antar generasi dari segi non-genetik, yaitu faktor ibu seperti gizi, riwayat penyakit, stress, serta pola asuh yang berdampak pada pertumbuhan anak. ${ }^{26}$ Secara spesifik, faktor gizi dapat menentukan capaian pertumbuhan dari potensi genetik tinggi badan, terutama pada populasi di negara berkembang. ${ }^{29}$ Tinggi badan seorang ibu tidak hanya merefleksikan genetiknya, melainkan juga riwayat pola makan sebelumnya. ${ }^{30}$ Tinggi badan ibu dapat dijadikan sebagai marker yang berguna untuk mengkaraterisasi hubungan status kesehatan antar generasi karena tinggi badan mencerminkan akumulasi status kesehatan seorang ibu selama tahapan kehidupannya, khususnya terkait dengan paparan sosial dan lingkungan di masa anakanaknya. ${ }^{31}$ Lebih jauh lagi, kombinasi antara faktor genetik, lingkungan dan perubahan epigenetik yang sama antara orang tua dan anak juga dapat berkontribusi terhadap pertumbuhan orang tua dan keturunannya. $^{32}$

Penelitian ini mampu mengidentifikasi tinggi badan ibu sebagai faktor risiko stunting pada anak usia 24-59 bulan. Tinggi badan anak dan ibu diukur melalui pengambilan data secara langsung sehingga menghilangkan risiko bias recall yang dapat diakibatkan oleh rancangan penelitian kasus kontrol. Namun, selain variabel tinggi badan ibu, analisis statistik hanya dilakukan pada variabel sosial ekonomi seperti tingkat pendidikan ibu, tingkat pendidikan ayah, dan jenis pekerjaan ayah. 
Kemungkinan adanya pengaruh dari variabelvariabel luar seperti riwayat asupan gizi, status gizi dan penyakit infeksi pada ibu selama kehamilan, serta tingkat ekonomi rumah tangga dapat terjadi.

\section{SIMPULAN}

Pada penelitian ini disimpulkan bahwa ibu dengan tinggi badan pendek $(<150 \mathrm{~cm})$ berisiko lebih besar untuk memiliki anak yang stunting. Temuan ini mengindikasikan adanya siklus malnutrisi antar generasi dari ibu ke anak. Program pencegahan stunting mulai dari 1000 hari pertama kehidupan sebaiknya menjadi prioritas dalam penanganan masalah stunting di Indonesia.

\section{UCAPAN TERIMA KASIH}

Peneliti berterima kasih kepada LLDIKTI Wilayah V Yogyakarta 2017/2018 atas hibah penelitian yang diberikan bagi penelitian ini.

\section{DAFTAR PUSTAKA}

1. UNICEF WHO and World Bank Group. Levels and trends in child malnutrition: Key findings of the 2019 edition. UNICEF, World Health Organization, World Bank Group. 2019

2. NIHRD. Laporan Nasional Riskesdas 2018. available

from http://www.kesmas.kemkes.go.id/assets/upload/ dir_519d41d8cd98f00/files/Hasil-riskesdas-

2018_1274.pdf?opwvc=1 (2019, accessed 2019 Sep 27).

3. Bappenas and UNICEF. SDG Baseline Report on Children in Indonesia. Jakarta: BAPPENAS and UNICEF. 2017.

4. Meylia KN, Siswati T, Paramashanti BA, et al. Fine motor, gross motor, and social independence skills among stunted and nonstunted children. Early Child Dev Care 2020: 18.

5. de Onis $\mathrm{M}$, Borghi $\mathrm{E}$, Arimond $\mathrm{M}$, et al. Prevalence thresholds for wasting, overweight and stunting in children under 5 years. Public Health Nutr 2018; 22: 175-179.

6. World Bank Group. Aiming high: Indonesia's ambition to reduce stunting. Washington: World Bank, 2018.

7. TNP2K. 100 kabupaten/kota prioritas untuk penanganan stunting. Jakarta: National Team for the Acceleration of Poverty Reduction (TNP2K), 2017.

8. TNP2K. 160 kabupaten/kota prioritas dengan masing masing 10 desa untuk penanganan stunting/kerdil. Jakarta, Indonesia: TNP2K and Ministry of National Development Planning/ National Development Planning Agency. 2018.
9. Prendergast AJ and Humphrey $\mathrm{JH}$. The stunting syndrome in developing countries. Paediatr Int Child Health 2014; 34: 250-265.

10. Nshimyiryo A, Hedt-Gauthier B, Mutaganzwa $\mathrm{C}$, et al. Risk factors for stunting among children under five years: a cross-sectional populationbased study in Rwanda using the 2015 Demographic and Health Survey. BMC Public Health 2019; 19: 175.

11. Paramashanti BA, Paratmanitya $\mathrm{Y}$ and Marsiswati. Individual dietary diversity is strongly associated with stunting in infants and young children. Jurnal Gizi Klinik Indonesia, 2017; 14: 19-26.

12. Khasanah DP, Hadi $\mathrm{H}$ and Paramashanti BA. Waktu pemberian makanan pendamping ASI (MP-ASI) berhubungan dengan kejadian stunting anak usia 6-23 bulan di Kecamatan Sedayu. Indonesian Journal of Nutrition and Dietetics 2016; 4: 105-111.

13. Stewart CP, Iannotti L, Dewey $\mathrm{KG}$, et al. Contextualising complementary feeding in a broader framework for stunting prevention. Matern Child Nutr 2013; 9: 27-45.

14. Manggala AK, Kenwa KWM, Kenwa MML, et al. Risk factors of stunting in children aged 2459 months. Paediatr Indones 2018; 58: 205-213.

15. Fitriahadi E. Hubungan tinggi badan ibu dengan kejadian stunting pada balita usia 24 -59 bulan. Jurnal Kedokteran dan keseharan, 2018; 14: 1524.

16. Hanum NH. Hubungan tinggi badan ibu dan riwayat pemberian MP-ASI dengan kejadian stunting pada balita usia 24-59 bulan. Amerta Nutrition 2019: 78-84.

17. Hanum F, Khomsan A and Heryatno Y. Hubungan asupan gizi dan tinggi badan ibu dengan status gizi anak balita. J Gizi Pangan 2014; 9: 1-6.

18. Kusuma KE and Nuryanto. Faktor risiko stunting pada anak usia 2-3 tahun (Studi di Kecamatan Semarang Timur). Journal of Nutrition College 2013; 2: 523-530.

19. de Onis M and Branca F. Childhood stunting: a global perspective. Matern Child Nutr 2016; 12 Suppl 1: 12-26. 2016/05/17.

20. Victora CG, De Onis M, Hallal PC, et al. Worldwide timing of growth faltering: Revisiting implications for interventions. Pediatrics 2010; 125: e473-e480.

21. Lemeshow S, Hosmer DW, Klar J, et al. Adequacy of sample size in health studies. World Health Organization (WHO), 1990.

22. WHO. WHO Child Growth Standards: length/heightfor-age, weight-for-age, weightfor-length, weight-for-height and body mass 
index-for-age: methods and development. Geneva: World Health Organization, 2006.

23. Nasikhah $R$ and Margawati A. Faktor risiko kejadian stunting pada balita usia 24-36 bulan di Kecamatan Semarang Timur. Journal of Nutrition College 2012; 1: 176-184.

24. Bork KA and Diallo A. Boys are more stunted than girls from early infancy to 3 years of age in rural senegal. J Nutr 2017; 147: 940-947.

25. Paramashanti BA, Hadi $\mathrm{H}$ and Gunawan IMA. Pemberian ASI eksklusif tidak berhubungan dengan stunting pada anak usia 6-23 bulan di Indonesia. Indonesian Journal of Nutrition and Dietetics 2015; 3: 162-174.

26. Prado EL, Yakes Jimenez E, Vosti S, et al. Path analyses of risk factors for linear growth faltering in four prospective cohorts of young children in Ghana, Malawi and Burkina Faso. BMJ Glob Health 2019; 4: e001155.

27. Alderman $\mathrm{H}$ and Headey D. The timing of growth faltering has important implications for observational analyses of the underlying determinants of nutrition outcomes. PLoS ONE 2018; 13. Article.

28. Supriyanto Y, Paramashanti BA and Astiti D. Berat badan lahir rendah berhubungan dengan kejadian stunting pada anak usia 6-23 bulan. Indonesian Journal of Nutrition and Dietetics 2018; 5: 23.

29. Addo OY, Stein AD, Fall CH, et al. Maternal height and child growth patterns. J Pediatr 2013; 163: 549-554.

30. Ahmed T, Hossain M and Sanin KI. Global Burden of Maternal and Child Undernutrition and Micronutrient Deficiencies. Ann Nutr Metab 2012; 61(suppl 1): 8-17.

31. Silventoinen K. Determinants of variation in adult body height. J Biosoc Sci 2003; 35: 263285.

32. Addo OY, Stein AD, Fall CHD, et al. Parental childhood growth and offspring birthweight: pooled analyses from four birth cohorts in low and middle income countries. Am J Hum Biol 2015; 27: 99-105.. 